\title{
Emotional distress and caregivers burden at the end of life
}

\author{
Limonero, Joaquín T.1 , Gómez-Romero, María José1,2, Maté-Méndez, Jorge ${ }^{1,3}$, Mateo Ortega, Dolors ${ }^{1,4}$, \\ Gil Moncayo, Francisco ${ }^{1,5}$, Álvarez-Moleiro, María ${ }^{1}$, Montes Hidalgo, Javier ${ }^{6}$, Tomás-Sábado, Joaquín ${ }^{6}$
}

1 Universitat Autònoma de Barcelona. Stress and Health Research Group (GIES). Faculty of Psychology. Bellaterra (Cerdanyola del Vallés). Barcelona. Spain. ${ }^{2}$ Psychology Unit. Egarsat, Mutua Colaboradora con la Seguridad Social no 276, Terrassa (Barcelona). Spain. ${ }^{3}$ Psycho-oncology Unit. Bellvitge Biomedical Research Institute (IDIBELL). Catalan Institute of Oncology. L’Hospitalet de Llobregat (Barcelona). ${ }^{4}$ Palliative Care Unit. Consorci Sanitari de Terrassa (Barcelona). Spain. ${ }^{5}$ Psycho-oncology Unit. Psychosocial Observatory in Cancer. Catalan Institute of Oncology. L'Hospitalet de Llobregat, (Barcelona). Spain, ${ }^{6}$ Gimbernat Nursing School. Universitat Autònoma de Barcelona. Research and Scientific Communication Unit. Sant Cugat (Barcelona). Spain

BACKGROUND: Caring for a loved one at the end of life, involve many changes in caregiver's life. Some of these changes are perceived in a negative way by caregivers experimenting burden and emotional distress.

AIM: We aim to analyse the relationship between emotional distress and caregiver burden in caregivers of patients at the end of life who receive palliative care.

METHODS: 136 caregivers with a mean age of 56.24 (SD =14.63; 84 women, 52 men) of patients at the end of life admitted to palliative care unit answered the scale of Detection of Emotional Distress Caregivers (DED-C) ${ }^{1}$ and the Reduced Zarit Scale (RZS) ${ }^{2}$ also of demographics variables were recorded.

\section{RESULTS}

$>$ More than half of caregivers (54\%) had moderate to severe burden and emotional distress.

$>$ We observed a positive statistically significant correlation between emotional distress and overall caregivers burden and with all its subscales (Table 1)

$>$ We didn't find any differences between gender in relation to emotional distress or global caregiver burden. Only we observed statically differences in relation to self-care, where women were more worried about this dimension $(t=-2.76 ; d f=134 ; p<.01)$.

$>$ Caregivers who presented emotional distress showed more perception of burden [global score of reduced Zarit $(t=-2.78$; $p<.01)$ ] and in two of their dimensions: loss of role $[t=-2.17 ; d f=134 ; p<.01]$ and caregiver burden $[t=-2.43 ; d f=134 ; p<.05]$. We didn't observe statistic differences in the dimension of self-care $(t=-1,48 ; d f=134 ; p>.05)$ of the reduced Zarit.

Table 1. Correlation matrix

\begin{tabular}{cccccc}
\hline & $M(S D)$ & $\begin{array}{c}\text { Emotional } \\
\text { distress }\end{array}$ & Overall Zarit & Burden Z & Self Care Z. \\
$\begin{array}{c}\text { Emotional } \\
\text { distress }\end{array}$ & $11,26(4.22)$ & & & \\
Overall Zarit & $18.73(7.5)$ & $.409^{* *}$ & & \\
Burden Zarit & $8.36(4.9)$ & $.373^{* *}$ & $.883^{* *}$ & \\
Self-care Zarit & $5.3(2.02)$ & $.237^{* *}$ & $.636^{* *}$ & $.358^{* *}$ & \\
$\begin{array}{c}\text { Loss of role } \\
\text { Zarit }\end{array}$ & $4.98(2.72)$ & $.278^{* *}$ & $.705^{* *}$ & $.376^{* *}$ & $.380^{* *}$ \\
\hline
\end{tabular}

\section{DISCUSSION}

$>$ Most caregivers of patients at the end of life presented emotional distress and burden which affects their wellbeing, the adaptation to their role as caretaker as well as patient support.

$>$ Taking attention to the relation of emotional distress and caregivers burden could help health professional to prevent this situation by providing psychological and social resources to caregivers and improve their wellbeing and the adaptation to this situation.

$>$ Our results justify the systematic assessment of emotional suffering and the levels of burden of the primary caregivers.

** $p<.001$

\section{REFERENCES}

1. Limonero JT, Maté J, Mateo D, González-Barboteo J, Bayés R, Bernaus M, Casas C, López M Sirgo A, Viel S. Sánchez C, Gómez-Romero MJ, Álvarez M., Tomás-Sábado, J. Desarrollo de la escala DME-C: una escala para la detección del malestar emocional de los cuidadores principales de personas con enfermedad avanzada o al final de la vida [Development of the DME-C scale: a scale for the detection of emotional distress of the main caregivers of people with advanced or end-of-life illness]. Ansiedad Estrés. 2016; 22(2):104-9. http://dx.doi.org/10.1016/j.anyes.2016.09.00152.

2. Gort, A. M., March, J., Gomez, X., de Miguel, M., Mazarico, S., and Balleste, J. (2005). Short Zarit scale in palliative care. Med. Clin. 124, 651-653. doi: 10.1157/13074742 